\title{
Erratum to: Modulation of diffusion with polarized lasers
}

\author{
Sen-Yong Chen • Othmane Benafan • \\ Raj Vaidyanathan · Aravinda Kar
}

Published online: 6 August 2014

(c) Springer-Verlag Berlin Heidelberg 2014

\section{Erratum to: Appl. Phys. A (2014) 116:703-713 \\ DOI 10.1007/s00339-014-8505-1}

Due to a processing error, the presentation of Fig. $8 \mathrm{a}$ was incorrect. The corrected Fig. 8 is given below.
The online version of the original article can be found under doi:10.1007/s00339-014-8505-1.

\section{S.-Y. Chen · A. Kar $(\bowtie)$}

Laser-Advanced Materials Processing Laboratory, CREOL, The College of Optics and Photonics, University of Central Florida, 4000 Central Florida Blvd, Orlando, FL 32816, USA

e-mail: akar@creol.ucf.edu

O. Benafan $\cdot$ R. Vaidyanathan

Advanced Materials Processing and Analysis Center (AMPAC), Mechanical, Materials, and Aerospace Engineering, University of Central Florida, 4000 Central Florida Blvd, Orlando,

FL 32816, USA

e-mail: othmane.benafan@nasa.gov

R. Vaidyanathan

e-mail: raj@ucf.edu

Present Address:

O. Benafan

Structures and Materials Division, NASA Glenn Research

Center, Cleveland, $\mathrm{OH} 44135$, USA
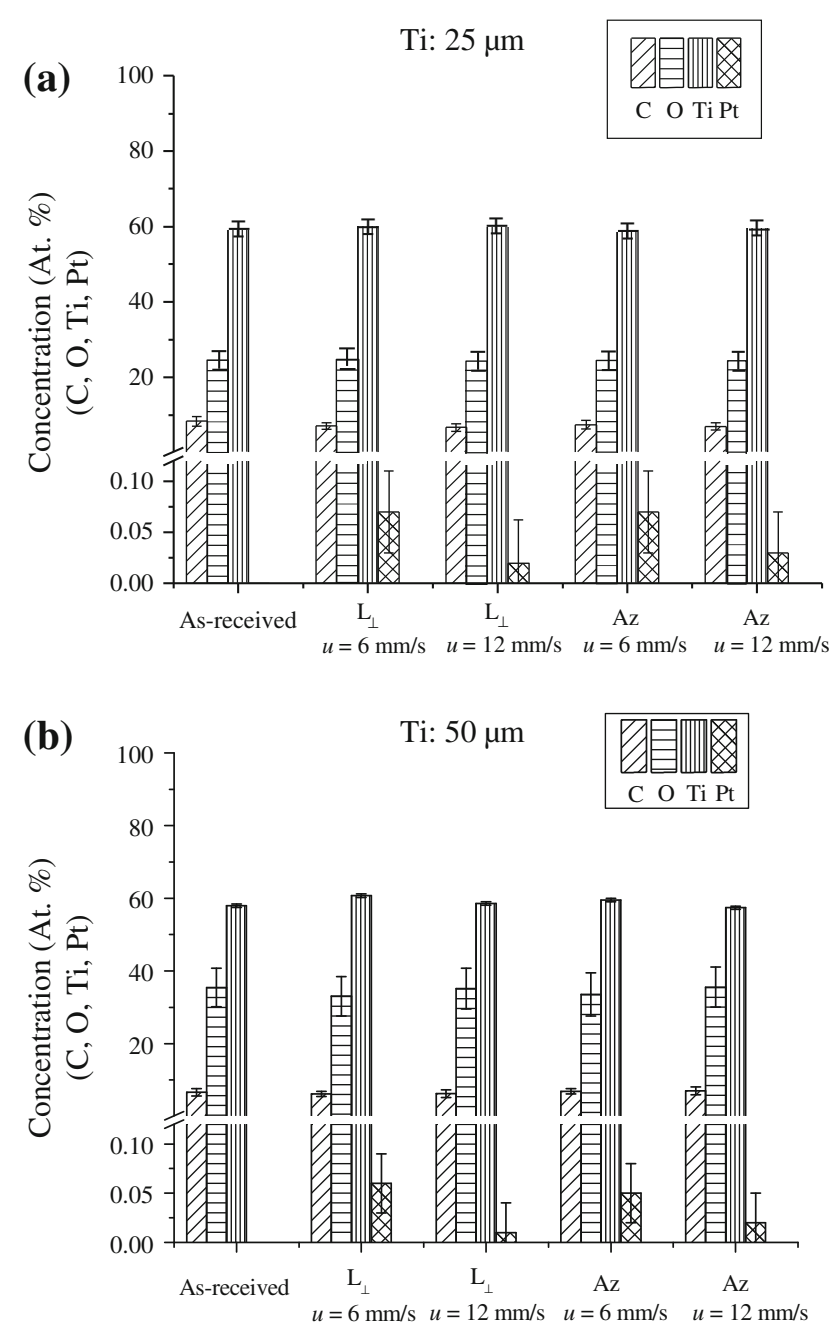

Fig. 8 Concentrations of different elements in laser-treated, a $25 \mu \mathrm{m}$-thick and b $50 \mu \mathrm{m}$-thick Ti samples 